4. EL ESTADO DE PARTIDOS Y ALGUNAS CUESTIONES DE DERECHO ELECTORAL

\author{
ÁNGEL RODRÍGUEZ DÍAZ \\ Profesor Titular de Derecho Constitucional \\ Universidad de Málaga
}




\title{
SUMARIO
}

\begin{abstract}
INTRODUCCIÓN Y PROPUESTA METODOLOGICA.-I. EL ESTADO DE PARTIDOS Y EL REGISTRO DE PARTIDOS POLITICOS.-II. EL ESTADO DE PARTIDOS Y LAS CANDIDATURAS ELECTORALES.-III. EL ESTADO DE PARTIDOS Y LA CAMPANAA ELECTORAL.-IV. EL CONTROL DE LA INCIDENCIA DEL ESTADO DE PARTIDOS SOBRE EL PROCESO ELECTORAL.-REFERENCIAS BIBLIOGRAFICAS.
\end{abstract}


Revista de Derecho Político, núm. 31, 1990, pp. 89-122

\section{EL ESTADO DE PARTIDOS Y ALGUNAS CUESTIONES DE DERECHO ELECTORAL}

ANGEL RODRIGUEZ DIAZ

Universidad de Málaga

INTRODUCCIONN Y PROPUESTA METODOLOGICA

Nos proponemos con este trabajo analizar la incidencia que la constitucionalización de los partidos políticos tiene en el régimen electoral vigente, regulado fundamentalmente por la Ley Orgánica $5 / 85$, del. Régimen Electoral General (LOREG). Para ello, por lo que atañe a las funciones de los partidos en el proceso electoral, es necesario considerar, la atribución funcional que se deduce del artículo $6 \mathrm{CE}$, cuando regula que «los partidos políticos (...) concurren a la formación y manifestación de la voluntad popular... »

Traduciéndolas a términos políticos, las funciones que el artículo 6 CE constitucionaliza para los partidos en relación con la representación política pueden asimilarse a dos momentos de la relación representativa:

a) el momento de la creación de la representación y b) el momento de la administración de la representación. Así, a) durante el momento de la creación de la representación, que coincide con el proceso electoral, los partidos concurren a la formación de la voluntad popular; b) durante el momento de la administración de la representación, que coincide con la actuación de los representantes, los partidos concurren a la manifestación de la voluntad previamente formada. Estos dos momentos de la relación representativa se desarrollan, por lo tanto, en dos tipos de instituciones propias de los regímenes constitucionales: las elecciones y las asambleas representativas. Nos ceñiremos, en consecuencia, sólo a la atribución fun- 
cional que el artículo $6 \mathrm{CE}$ encomienda a los partidos en orden a «concurrir a la formación (...) de la voluntad popular» '.

Nuestra propuesta metodológica para analizar el ejercicio por los partidos de sus funciones constitucionales en relación con el proceso electoral como momento inicial de la relación representativa, inserta la relación entre partidos y representación en un marco más amplio de relaciones: las que pueden darse entre la garantía institucional de los partidos políticos (art. 6 CE) y los derechos fundamentales de asociación (art. 22 CE) y de participación por medio de representantes (art. $23 \mathrm{CE}$ ).

En este sentido, consideramos que el artículo 6 CE incorpora, para nuestro texto constitucional, una garantía institucional sobre los partidos políticos. Esta garantía institucional recoge, a su vez, dos principios completamentarios: a) un principio de constitucionalización de los partidos y b) un principio de constitucionalidad de los partidos (la distinción, en DE VEGA, 1977).

a) El principio de constitucionalización se contiene en el primer párrafo del artículo 6 CE y consiste en una atribución funcional en virtud de la cual la Constitución encomienda a los partidos el ejercicio de determinadas funciones constitucionalmente relevantes. Según la literalidad del artículo $6 \mathrm{CE}$, éstas consistirian en expresar el pluralismo político, concurrir a la formación y manifestación de la voluntad popular y ser instrumento fundamental para la participación política.

b) El principio de constitucionalidad se desprende del segundo párrafo del mismo artículo y consiste en las cargas que la propia Constitución establece sobre la atribución funcional que acaba de regular: actuar dentro del respeto a la Constitución y a la Ley y con una estructura interna y un funcionamiento democráticos.

La existencia de estos dos principios, presentes también, aunque con diversas modalidades, en el derecho comparado, y la previa realidad política e histórica que se encuentra detrás de la recepción constitucional de los partidos, nos permiten hablar de la garantía institucional del artículo 6 $\mathrm{CE}$, asi considerada, como una garantía institucional del Estado de Partidos. En efecto, aún dentro de la casuística que la expresión «Estado de Partidos» incorpora como reflejo de regimenes constitucionales diferentes (ver GARCIA PELAYO, 1986), es posible encontrar algunos puntos comunes y -éste es el sentido de nuestra propuesta metodológica- esenciales, que carac-

1 Para un análisis de los problemas que se derivan de la concurrencia de los partidos a la «manifestación» de la voluntad popular, ver TORRES DEL MORAL, 1982. 
terizan esa realidad política y constitucional, esto último desde su recepción por el constitucionalismo de posguerra europeo (entre nosotros desde la aprobación de la $\mathrm{CE}$ ).

Que la recepçión constitucional de los partidos políticos pretende consagrar el pluralismo de partidos está fuera de duda. En ese sentido, se muestra como reacción a la inicial consideración constitucional del partido político que se da en los regímenes autoritarios del periodo entreguerras y que consagran un Estado de Partido Unico. El hecho de que la crisis política de este periodo de la historia europea se hubiera propiciado, precisamente, mediante la destrucción del Estado Constitucional por la acción de un partico anticonstitucional no es una paradoja, sino precisamente el sentido de la constitucionalización de los partidos políticos en algunos países europeo al final de la guerra.

El reforzamiento del protagonismo de los partidos se complementa en ese momento, por esta razón, con cierto control del Estado sobre su carácter democrático, que se desarrolla en una u otra dirección, a veces en un sentido polémico según cada caso (controles ideológicos del estilo de mecanismos de "Defensa de la Constitución», controles de democraticidad interna, controles de tipo financiero, etc). En cualquier caso, la realidad política del Estado de Partidos incorpora esa doble visión acerca de los partidos: protagonismos y control. Si relacionamos todo ello con la presencia del doble principio de constitucionalización y constitucionalidad, como su traslación jurídico-constitucional, podremos concebir el Estado de Partidos como el objeto protegido mediante la garantía institucional del artículo $6 \mathrm{CE}$.

Por otra parte, concebir la garantía institucional del artículo $6 \mathrm{CE}$ como una integración de estos dos elementos permite, además, relacionarlos entre sí, partiendo de que uno de ellos actúa como la necesaria compensación al otro: Del desarrollo constitucional de cada uno de ellos, y de su capacidad para disciplinar el régimen juridico de determinados derechos fundamentales, se puede, por lo tanto, deducir la existencia o no de cierto equilibrio entre los dos elementos de la garantía institucional.

En efecto, la consecuencia típica de la incidencia de una garantía institucional sobre el régimen juridico de algunos derechos fundamentales relacionados con el objeto garantizado es una tendencia a la «funcionalización» (OLLERO, 1949) al «debilitamiento» (RUBIO LLORENTE, 1979) de sus condiciones de ejercicio, que se pliegan al sentido propio en el que la garantía institucional se establece, o a los "ciertos fines a los que sirve», en palabras de Carl SCHMITT $(1928,175)$. Para el caso que nos ocupa, interesa analizar la relación entre la garantía institucional del artículo $6 \mathrm{CE}$ y los derechos fundamentales de asociación y participación política. Al consistir la garantía institucional del Estado de Partidos en dos elementos simultáneos, la vis atractiva de la garantía institucional atrae hacia si el régimen jurídico del ejercicio de estos derechos, bien potenciándolos cuando 
se ejercen bajo modalidades partidarias, $y$, consecuentemente, debilitando su ejercicio bajo otras modalidades (efecto de constitucionalización), bien arbitrando determinadas cargas sobre ellos cuando se ejercen bajo la modalidad de partido político (efecto de constitucionalidad).

Desde esta perspectiva, y dada la incidencia del protagonismo de los partidos sobre un aspecto determinado del sistema político o del régimen constitucional, cabe plantearse si ese protagonismo se encuentra en una situación equilibrada o en una situación de desequilibrio. Podemos atender, para ello, a tres criterios:

1. Si existe o no regulación constitucional sobre el particular, es decir, si se ha incluido ese aspecto en la recepción constitucional del Estado de Partidos. Sabemos, por ejemplo, que no existen previsiones constitucionales sobre el «enlazamiento» entre el partido y sus representados durante el tiempo de duración del mandato (ver el concepto de "enlazamiento" en LAWSON, 1980, y un desarrollo en RODRIGUEZ DIAZ, 1987). Debido a ello, un importante elemento de la relación representativa queda fuera de la aspiración normativa sobre las funciones de los partidos que se introduce en el derecho constitucional con la garantía institucional del Estado de Partidos. Como esta laguna constitucional no conlleva, ni mucho menos, que no se produzca en ese punto del proceso representativo una fuerte incidencia de los partidos, la actuación de éstos se encuentra sin ningún parámetro jurídico al que sujetarse. Como es evidente, éste no es el caso del proceso electoral como momento inicial de la relación representativa, ya que existen previsiones jurídicas sobre la incidencia de los partidos en el desarrollo de las elecciones políticas. Pero, y ello también es evidente, del hecho de que exista alguna regulación jurídica no se deduce, sin más, que no exista desequilibrio.

2. El segundo criterio para apreciar una situación de equilibrio o desequilibrio viene dado por el análisis del elemento de la garantía institucional del Estado de Partidos cuya presencia sea más fuerte en la regulación existente: teniendo en cuenta los dos objetivos que persigue la garantia, asegurar el protagonismo de los partidos en el sistema político y asegurar que en ese protagonismo la labor de los partidos se sujetará a cierto control, puede ocurrir: $i$ ) que se encuentre más desarrollado el primero, asegurando que la constitucionalización de atribuciones funcionales a los partidos debilita las modalidades de ejercicio de los derechos de asociación y de participación que adoptan formas no partidarias; ii) que se encuentre más desarrollado el segundo, asegurando que los criterios de constitucionalidad que operan sobre los partidos impongan determinadas cargas a esos derechos fundamentales cuando se ejercen bajo modalidades partidistas; iii) que exista una situación compensada entre los dos, de manera que los criterios de constitucionalidad operen como contrapeso del 
protagonismo que se deduce de la constitucionalización de atribuciones funcionales.

3. El tercer criterio a utilizar viene dado por la existencia de mecanismos, definidos y posibilitados por el ordenamiento jurídico, mediante los cuales se pueda controlar, por parte de los propios ciudadanos, en tanto que titulares de derechos subjetivos, la posible lesión del contenido esencial de sus derechos fundamentales que pueda producirse como consecuencia de una excesiva atracción del régimen jurídico de su ejercicio por parte de la garantía institucional, debilitando, mediante el principio de constitucionalización, las modalidades no partidarias de esos derechos fundamentales, e introduciendo, mediante el principio de constitucionalidad, determinadas cargas en las modalidades ejercicidas bajo la forma de un partido político.

Por otra parte, si entendemos por creación de la representación la primera parte de la función de concurrencia de la que habla del artículo 6 CE (... concurren a la formación [...] de la voluntad popular), no cabe duda de que el momento adecuado para analizar la incidencia de los partidos en este momento de la relación representativa, aplicando ahí nuestro esquema de análisis, es el proceso electoral. Existen al menos tres razones para ello:

a) En primer lugar, las elecciones son el primer momento de la relación representativa, tal como ésta la entendemos en la actualidad. La conjugación de dos conocidos factores, a saber, la imposibilidad práctica de la democracia directa y la progresiva vinculación de la selección del representante al momento de su elección, hacen del momento electoral el primer paso indispensable para la creación de una relación representativa democrática.

b) En segundo lugar, es evidente la vocación de los partidos de mediar en este momento electoral. Sabemos que esta mediación es una de las facetas más importantes de la mediación de los partidos en la relación representativa. Hay que precisar también que el factor electoral fue, así mismo, uno de los más importantes en el proceso de consolidación de los partidos en el sistema español que se da a lo largo de nuestra transición política.

c) En tercer lugar, las elecciones son, también, el momento del ejercicio de unos derechos fundamentales de contenido más amplio que el que pueden encauzar los partidos. No siempre (ver TORRES DEL MORAL, 1975; 185, y DE ESTEBAN, 1977; 11 y 342), pero sí desde la progresiva conformación del sufragio como derecho, en el momento electoral convive un procedimiento de selección de representantes con el ejercicio de derechos subjetivos de los ciudadanos. Se dan, por lo tanto, las condiciones 
para analizar las relaciones entre la garantia institucional del Estado de Partidos y los derechos fundamentales según el modelo que hemos propuesto.

Es posible, por lo tanto, aplicar en este punto los tres criterios que ayudan a definir el equilibrio o desequilibrio existente en el protagonismo electoral de los partidos. Hay que analizar, por lo tanto: 1) la existencia o no de previsiones constitucionales: 2) la compensación o descompensación entre los dos elementos de la garantia institucional del Estado de Partidos y 3) la existencia o no de controles sobre la incidencia de la garantía sobre los derechos fundamentales.

1) Como queda dicho, es evidente que sí existen previsiones constitucionales y desarrollo legislativo sobre el momento de creación de la representación. Es aún de fecha reciente (19 junio 1985) la aprobación de la Ley Orgánica del Régimen Electoral General (LOREG). La LOREG se ocupará, por lo tanto, de regular todo lo concerniente a la incidencia de los partidos sobre este primer momento de la relación representativa.

La LOREG es heredera directa del Real Decreto Ley de 18 de marzo de 1977 que reguló las elecciones durante los momentos de la Transición y durante las dos primeras legislaturas constitucionales. Quizá por esta vigencia excesiva, más allá de lo inicialmente previsto, lo cierto es que el núcleo esencial de aquel Decreto-Ley sigue presente en la LOREG, lo que, como veremos, tiene no escasa relevancia para la incidencia de los partidos durante todo el proceso electoral.

La permanencia del Decreto-Ley en la nueva normativa es bien patente, incluso a primera vista. Hay un primer dato significativo: la aprobación de la LOREG se debió en gran parte -ese fue su «auténtico acicate» (ÁLVAREZ CONDE-GONZÁLEZ HERNÁNDEZ, 1985; 34), su «detonante decisivo" (FERNÁNDEZ SAGADO, 1985; 24) - a la necesidad de aprobar una Ley de incompatibilidades de diputados y senadores. La previsión constitucional (art. $70 \mathrm{CE}$ ), reforzada con la interpretación del Tribunal Constitucional (STC $72 / 84$ de 14 de junio), de que estas incompatibilidades deberían incluirse en una Ley Electoral, obligó a iniciar los trámites para la aprobación de la nueva Ley.

Por otro lado, el expreso reconocimiento de la vinculación entre las dos normas, proclamado en sede legislativa ${ }^{2}$ desdice en gran parte la idea

2 Con motivo de la aprobación del proyecto en el Congreso, el Vicepresidente del Gobierno, D. Alfonso Guerra (Diario de Sesiones,.$^{\circ} 174$, pág. 8068) realizó una alabanza expresa de la conexión entre las dos normas. Dijo: “No es, por tanto, (el proyecto de LOREG) un proyecto que signifique un vuelco total, un nuevo sistema 
de que el prolongado periodo de vigencia de la primera se debiera sólo a la «inercia» de los legisladores (ÁLVAREZ CONDE - GONZÁLEZ HERNÁNDEZ, 1985; 30) o que éste constituyera «una de las decisiones políticas más erróneas de nuestro proceso de Transición» (id. 33). Por el contrario, parece que aquí de nuevo se cumple la idea de LAWSON (1978) sobre el carácter acomodaticio de los partidos, en concreto, sobre la acomodación inmediata que hacen una vez en el poder para tratar de garantizar su permanencia en él, modofificando lo que haya que modificar de la legislación electoral.

Si pensamos que el Decreto-Ley de 1977 estuvo en vigor bajo gobiernos de partidos diferentes (en 1977 y 1979, gobierno de la UCD; en 1982, gobierno del PSOE) y que su sustitución no ha cambiado mucho la mayoría de las cosas, puede aventurarse la conclusión de que lo que en él habia que cambiar no era, en realidad, demasiado.

El continuismo de la LOREG con respecto al Decreto-Ley de 1977 es pues, evidente; ÁLVAREZ CONDE-GONZÁLEZ HERNÁNDEZ (1985; 29) lo cifran, sobre todo, en el mantenimiento de la provincia como circunscripción electoral y de las fórmulas electorales para el Congreso y el Senado. CAZORLA PRIETO $(1986 ; 21)$ lo extiende a todo el contenido de la nueva Ley, excepción hecha de las modificaciones introducidas en la Administración Electoral, el control de gastos electorales y la redistribución del número de escaños por provincia. FERNÁNDEZ SEGADO $(1986 ; 26)$ llega a afirmar que, en realidad, no puede decirse que nos encontremos ante una «nueva» ley electoral, si entendemos por tal «una normativa que se separa sustancialmente de la precedente». En cualquier caso, entre las notas que confirman la continuidad entre uno y otro régimen electoral se encuentra su funcionalidad para garantizar el poder de los partidos políticos importantes.

global electoral. En este sentido, hemos partido de un dato que nos parece políticamente relevante: la inmensa mayoría de los ciudadanos españoles hemos aprendido a utilizar nuestro derecho al sufragio con el decreto-ley de 1977, y es cierto que una modificación en profundidad de este sistema seria en parte difícilmente posible, dado que la Constitución recogió en sus líneas generales el contenido de aquel decreto-ley, y se puede, lógicamente, modificar algunas cosas, porque la Constitución lo permite, pero los resultados no serían nunca sustanciales, sino más bien relativos o accesorios (...) Hoy está fuera de toda discusión la innegable funcionalidad del decreto-ley de 1977 para la consolidación del sistema democrático en lo que hace referencia a lo electoral en España. El hecho de que aquel texto, el decreto-ley de 1977, haya permitido estructurar de forma democrática, permitiendo la alternancia en el poder, incluso el logro de mayorías absolutas, se ha mostrado a nuestro juicio, como un sensible instrumento de recepción de los cambios políticos que se han operado y que pueden operarse en nuestro país" (citado por CAZORLA PRIETO, 1986; 27). Una opinión discordante, por ejemplo, en el discurso del mismo día del diputado Sr. Bandrés: «Esta ley ni reforma ni abre el sistema representativo, $y$, conformándose con lo que funciona hasta ahora, no profundiza la legitimación política ni integra satisfactoriamente los relevantes descontentos que subyacen a este sistema politico". (Diario de Sesiones, n. ${ }^{\circ} 174$ pág. 8067; citado también por CAZORLA PRIETO, 1986; 27). 
2) ¿Qué significa en la práctica esta continuidad? Inmediatamente lo veremos, pero podemos ya adelantar que se confirma y se consolida la constitucionalización de la mediación de los partidos en el proceso electoral. Pero el segundo elemento de la garantía institucional, los criterios de constitucionalidad, no se ven tan confirmados. Evidentemente, esto contribuye a consolidar la situación de protagonismo de los propios partidos como tales. No de otra forma puede conjugarse el amplio consenso parlamentario logrado en su aprobación (239 votos a favor de un total de 243, con dos votos en contra y dos abstenciones) con la extendida tesis de que el régimen electoral es siempre una expresión de fuerza (NOHLEN, 1978; 16-20) que favorece a quienes lo elaboran (CARRERAS-VALLÉS, 1977; 24).

De esta forma, la LOREG recoge sobre todo las atribuciones funcionales de los partidos en el proceso electoral, pero casi en nada las cargas que los criterios de constitucionalidad llevan consigo. Esta atribución funcional revela el protagonismo de los partidos en una serie de funciones que les son propias a lo largo del proceso electoral (ver BASTIDA et. al., 1980; 216-18): i) funciones previas, como la elaboración de candidaturas y programas; por lo tanto, previas sólo desde un punto de vista procesual, pero no anteriores o exteriores a las elecciones ${ }^{3}$. Y ii) funciones realizadas durante el momento electoral, como la presentación de candidaturas, la camapña electoral y el propio control de las elecciones.

Es evidente la irrupción de los partidos, mediante esta atribución funcional, en todo el proceso electoral regulado por la LOREG. Se confirma que éstos han pasado, de ser un puente entre elegibles y elegidos, a erigirse en verdaderos sustitutos de aquéllos (BASTIDA, et. al., 1980; 215). La irrupción problematiza, como sabemos, la propia calificación que se otorga al proceso electoral, y haria necesarios unos nuevos planteamientos que sólo muy parcialmente incorpora la nueva Ley. En concreto, se echa de menos una eficiente incorporación de los criterios de constitucionalidad de los partidos, sin los que el desarrollo electoral de la garantía institucional queda coja. Estas deficiencias se encuentran en los dos posibles criterios de constitucionalidad de los que habla la Constitución:

3 Ya VIRGa $(1984 ; 122)$ hablaba de dos fases en las elecciones, la «preelección» y la «votación». La primera era la selección de candidatos llevada a cabo por el partido. Así, esta primera fase se caracterizaba por «una preelezione, mediante la cuale dai vari gruppi politici venisse operata una selezione preventiva delle candidatura. Tale delicato computo selettivo, affidato originariamente a cariche e gruppi locale, é stato sempre piú monopolizatto dai partiti via che questi ultimi si sono progresivamente sviluppatti in grandise organizzazioni capaci de sostenere validamente la candidatura da essi presceltem. 
A) En el caso del primer criterio del que habla el artículo $6 \mathrm{CE}$, el "respeto a la Constitución y a la Ley», asistimos a un intento de arbitrar un control específico - no ya en la LOREG sino en la Ley de Partidos Políticos- mediante la instauración de un Registro de Partidos. Como se sabe, este intento de control de constitucionalidad es tributario de la deficiente regulación constitucional sobre el particular y del intento de edificar ahí un control ideológico de los partidos, ignorando que la modalidad de la garantia institucional del Estado de Partidos que existe en nuestro sistema político no hace posible este tipo de control (ver DE OTTO, 1985).

B) Por lo que hace al segundo criterio de constitucionalidad, la estructura y funcionamiento interno democráticos, se desprecia la idoneidad de la LOREG para regular esta carga en lo que hace al momento electoral, esto es, en cuanto a la selección de los candidatos y elaboración de los programas electorales. Frente a posibles opiniones en contra de la conveniencia de desarrollar estos controles ahora, somos de la opinión, con ALBA (1986; 169), de que "el ordenamiento electoral es el lugar adecuado, en razón de la materia, para articular un sistema de protección de la voluntad de los afiliados a un partido político", y que su hipotético establecimiento hubiera supuesto "un gran avance (...) en el conjunto del proceso electoral».

Veremos inmediatamente cuál ha sido la incidencia de la garantía institucional del Estado de Partidos en el régimen electoral, atendiendo a tres casos concretos: I. la presencia de criterios de constitucionalidad mediante el Registro de Partidos; II. la presencia de atribuciones funcionales en la presentación de las candidaturas y III. la incidencia de la garantía sobre la campaña electoral.

3) Como tercer parámetro, hay que acudir, por último, a la existencia de posibles controles sobre las lesiones que la aplicación de la garantía institucional pudiera introducir en los derechos fundamentales de asociación y de participación. Se ha puesto ya de manifiesto la idoneidad de un instrumento de protección, el recurso de amparo, para garantizar el contenido esencial de estos derechos en tanto que se ejercen bajo modalidades partidistas y pudieran verse exarcebadamente debilitados por la existencia de criterios de constitucionalidad. Éste ha sido el caso de los intentos de instrumentar, a través del Registro, un control ideológico de los partidos políticos (ver STC de 2 de febrero de 1981). Sin embargo, no ha ocurrido otro tanto con las posibles lesiones que hayan podido provenir de los efectos de la constitucionalización de los partidos. Es decir, con las consecuencias debilitadoras de estos derechos cuando se ejercen en modalidades no partidarias. Ello se debe en parte, a que no se ha ejercido ninguna acción concreta sobre ello y, en parte, a que todo el entramado de control del proceso electoral que diseña la LOREG descansa, tanto en el 
nivel administrativo, como en el judicial, en el protagonismo de los propios partidos: en el primer caso como copartícipes de la administración electoral y en el segundo mediante las oportunas legitimaciones procesales para recurrir.

\section{EL ESTADO DE PARTIDOS Y EL REGISTRO DE PARTIDOS POLITICOS}

El principal efecto de la garantia institucional del Estado de Partidos sobre el derecho electoral, considerando éste en sentido estricto, viene de la mano de la incidencia de los partidos politicos en el derecho al sufragio, sobre todo desde el punto de vista pasivo. Esta incidencia puede "debilitar", como sabemos, determinados derechos; cuando el debilitamiento se da sobre algunas de las características básicas del derecho al sufragio -aquellas que, en conjunto, nos permiten hablar de un sufragio libre (ver NOHLEN, 1978; 74) — se hace aún más necesario investigar las posibles lesiones del contenido esencial del derecho que de la garantía pudieran deducirse.

La intervención de los partidos puede darse sobre todo en tres de estas características básicas del sufragio: su universalidad, su carácter igual y su carácter secreto. Evidentemente, estas características no son las mismas desde el punto de vista del sufragio activo que desde el sufragio pasivo: no es contrario al voto libre restringir más la universalidad del sufragio pasivo (ver HONLEN, 1978; 65) hablar de secreto desde el lado del sufragio pasivo es evidentemente imposible, etc. Pero la universalidad del sufragio pasivo sí puede verse vulnerada si se establecen requisitos exorbitados para poder ser cantidatos, o si el sistema electoral vulnera en la práctica el voto igual (id.; 68). Y la exigencia de determinadas firmas como aval para poder presentar una candidatura si ésta no es de un partido político (art. 46. 8 LOREG) sí puede vulnerar, en la práctica, el carácter secreto del voto (ver, para el caso alemán, ABENDROTH, 1964; 432 y la jurisprudencia del Tribunal Constitucional Federal allí citada).

En nuestro sistema constitucional, la garantia institucional del Estado de Partidos no puede impedir la universalidad del sufragio pasivo. No porque esta imposibilidad esté incluida en la recepción constitucional de la garantía, en concreto, en el régimen de la función de concurrencia a la formación de la voluntad popular, sino porque se le opone el derecho fundamental de participación política, de contenido más amplio que sus concretas modalidades partidistas, y cuyo contenido esencial se vería vulnerado si se contemplara el monopolio funcional de los partidos en cuanto a ser cauces obligatorios para el sufragio pasivo. Ahora bien, ello no obsta para que el derecho sufra, si no una desaparición, si un debilitamiento, 
efecto típico de la incidencia sobre ellos de las garantías institucionales. En este sentido, el debilitamiento del sufragio pasivo puede venir: i) como efecto de la constitucionalización o ii) como efecto de la constitucionalidad. i) En el primer sentido, debilitando el sufragio pasivo no partidista; ii) en el segundo caso, debilitando, mediante las cargas de constitucionalidad, el propio sufragio pasivo encauzado por los partidos.

Dos han sido los instrumentos mediante los cuales se ha desplegado, o se ha intentado desplegar, esta incidencia: la instauración de un registro de partidos políticos y la existencia de un régimen diferente para las candidaturas, según sean o no partidistas. Veamos ahora el primero de ellos.

La existencia de un registro de partidos o, en general, de un registro de candidatos o candidaturas, puede tener cierta justificación primaria en la necesidad de dotar a éstas o a aquéllos de suficiente "seriedad" y de clarificar al panorama de opciones electorales ante los electores (ver CARRERAS-VALLÉS, $1977 ; 58-59$ ). El nuestro encuentra su cobijo constitucional en la previsión del artículo 22.3 CE acerca de un registro para las asociaciones, "a los solos efectos de publicidad" que ha sido interpretado por la Ley de Partidos Políticos de 1978, estableciendo (art. 2) un registro específico para éstos. Su existencia es tributaria, según DE OTTO (1985; 177-178) de la intención habida en algún momento de la Transición, de establecer un sistema de competencia restringida.

Este registro permitiría especificar aquellas candidaturas que se beneficiarían de la posición de protagonismo de los partidos (efecto de constitucionalización) y, a la vez, servir de instrumento para controlar la observancia por estas cantidaturas de las cargas constitucionales (efecto de constitucionalidad). Su desafortunada regulación ha venido a deparar que, en realidad, no haga ni lo uno ni lo otro.

a) Por lo que hace a sus efectos sobre la constitucionalización de los partidos, el Registro no puede impedir que concurran a las elecciones otras formaciones no inscritas, puesto que lo impide el derecho a la participación del artículo $23 \mathrm{CE}$. Sí puede servir de criterio para calibrar cuáles son las opciones electorales que se consideran como tales partidos, y por lo tanto, se benefician de su régimen particular.

b) En donde el Registro ha mostrado más su deficitaria articulación con el modelo constitucional del Estado de Partidos ha sido en la intención que ha existido para utilizarlo como mecanismo de control de constitucionalidad de los partidos. Aquí se han conjugado dos causas: en primer lugar, que el Registro es, como se ha dicho (JIMÉNEZ CAMPO, 1981; 181), el «presupuesto para el eventual control (posterior) del partido, pero no la ocasión para el mismo». $Y$, en segundo lugar, se ha querido realizar un tipo de control que queda fuera de los mecanismos de constitucionalidad que in- 
corpora en la CE la garantía institucional del Estado de Partidos; el control ideológico, que no puede existir entre nosotros ni con carácter previo ni con carácter posterior al hecho registral.

La previsión del artículo 22.3 CE acerca de un registro para las asociaciones «a los solos efectos de publicidad" y el registro específico para los partidos dispuesto en su virtud, no habilitan, por lo tanto, para introducir ninguna carga al derecho de asociarse en partidos, al menos ninguna carga mayor para los partidos que para las asociaciones. De esta forma, el registro de partidos debe entenderse también «a los solos efectos de publicidad" (DE OTTO, 1985; 106), al menos en lo que hace a los partidos como proyección de artículo 22 CE (otra cosa distinta es su relación con el artículo $23 \mathrm{CE}$, en cuya virtud el artículo $6 \mathrm{CE}$ establece, especialmente para los partidos, el requisito de la democracia interna como criterio de constitucionalidad).

La cuestión se complica aún más si intentamos poner en juego la normativa contenida en la Ley de Partidos. Su artículo $5.2, b$ ) contempla como uno de los casos tasados en los que se puede proceder a la disolución de los partidos, "cuando su organización o actividades sean contrarias a los principio democráticos».

En un primer momento, dominante la idea de que el artículo $22.2 \mathrm{CE}$ contenía una remisión directa al Código Penal, se afirmó que la alusión a las «actividades contrarias a los principios democráticos» era una interpretación errónea de la Ley, ya que la Constitución sólo contemplaba la posibilidad de prohibir los partidos ilícitos (art. $22 \mathrm{CE}$ ) y aquellos cuya organización interna y funcionamiento no fueran democráticos (art. $6 \mathrm{CE}$ ). Las "actividades" del artículo 5.2,b) de la Ley de Partidos, por lo tanto, no podían referirse a otra cosa que al «funcionamiento» interno del partido (JIMÉNEZ CAMPO, 1981). Esta interpretación era perfectamente coherente con la imposibilidad constitucional, ya demostrada, de que los principios de constitucionalidad de los partidos actuaran como mecanismos de «defensa de la Constitución» (id.; 177).

Sin embargo, descubierta la quiebra entre el derecho constitucional y la tipificación penal de las asociaciones ilícitas (ver DE OTTO, 1985; 6668) se abre una nueva posibilidad para la interpretación de las «actividades contrarias a los principios democráticos»: entrarian en esta categoria los partidos inconstitucionales por utilizar medios delictivos pero no violentos. Ahora bien, esta norma sólo sería aceptable para los casos en que estas actividades contrarias a los principios democráticos consistieran en utilizar medios tipificados como delito, ya que, de otro modo, la Ley de Partidos establecería una limitación a éstos sin fundamento constitucional ni en el artículo 22 CE ni en el artículo 6 CE (ver DE OTTO, 1985; 71). Así las cosas, gracias a la Ley de Partidos se abririan la posibilidad de disolver éstos aun no siendo ilícitos. Por lo que hace el resto de las asociaciones, persistiría 
la oscuridad acerca de la calificación de aquellas que la Constitución califica de ilegales, pero que no son asociaciones ilicitas $y$, por lo tanto, no pueden ser disueltas. En palabras DE OTTO (id.; 72), «sería posible disolver los partidos que hagan apología del terrorismo o que cometan delitos no violentos como los ultrajes a la bandera y cualesquiera otros", aunque, sin embargo, «no sería posible perseguir a sus miembros como autores de un delito de asociación ilícita en el sentido del Código Penal».

Si aceptamos que existe una posibilidad de disolución de los partidos en cuanto que asociaciones, entendiendo de esta manera las actividades contrarias a los principios democráticos, resultaria que habria una restricción del derecho de asociación en el caso de los partidos mayor que en el resto de las asociaciones. Esta mayor restricción entraría por la rendija que deja abierta la deficiente redacción del artículo 22.2 CE y se aprovecharía para sentar un nuevo criterio referente a las «actividades" de los partidos de las que habla la Ley de Partidos Políticos.

¿Estaría esta mayor restricción de acuerdo con la garantía institucional del Estado de partidos del artículo 6 CE? A nuestro juicio, no.

No cabe duda que uno de los objetivos al garantizar el Estado de Partidos es asegurar la posibilidad de algún mecanismo de control sobre ellos. Y que este principio de constitucionalidad de los partidos puede operar exigiéndoles a éstos una mayor sujeción al derecho constitucional que al resto de asociaciones; incluso, exigiéndoles una aceptación ideológica de la Constitución. Sin embargo, ésa no es la modalidad de constitucionalidad que se ha contemplado en la CE. Por esa razón, tampoco gozan los partidos de ninguno de los privilegios - como el de jurisdicción constitucional o el de prohibición previa que compensan esa mayor sujeción y la hacen mínimamente compatible con la seguridad juridica. En este sentido, el respeto a la Constitución incluido en la garantía institucional del artículo 6 CE no puede implicar mayor sujeción que la genérica del artículo $9.1 \mathrm{CE}$.

En esas circunstancias, si la propia CE quiere, puede establecer restricciones al derecho de asociación que no se identifiquen con las penales, por más que sea extremadamente difícil ver la voluntad del constituyente en la desafortunada literalidad del artículo $22.2 \mathrm{CE}$, en donde, sin duda, gana la partida la voluntas legis. Ahora bien, si, de la mano de esa posibilidad, se arbitra una vía para disolver exclusivamente los partidos, se introduce una restricción del derecho de asociación que no está en la línea de la modalidad en que la garantía institucional del Estado de Partidos se contempla en la CE. Aun en el caso de que fuera posible reconducir el concepto de eactividades contrarias al orden democrático" del artículo $5.2, b)$ de la Ley de Partidos a los casos de «utilizar medios delictivos - no violentos» (art. 22.2 CE/ art. 173.2 CP), disolver en su virtud partidos pero no asociaciones introduce un factor de constitucionalidad extraño a los perfiles de la garantía del artículo 6 CE. No sólo ello, sino que la confusión 
que puede originar supone una auténtica "puerta abierta para un uso que podría conmover los fundamentos del Estado de partidos" (DE OTTO, 1985; 70).

A pesar de ello, y completando por su cuenta el régimen de la constitucionalidad del partido, la Ley 54/78 establece ciertos mecanismos de control de los partidos en el propio hecho registral. Así, su artículo 3 faculta al Ministerio del Interior, de quien depende el Registro, a suspender la inscripción si de la documentación remitida por el partido se dedujeren «indicios racionales de ilictud penal», poniéndolo en conocimiento del Ministerio Fiscal, que dispondrá de veinte días para instar la declaración de ilegalidad. En el caso de que lo hiciera, el partido quedaría sin inscribir hasta que se solventara el proceso.

La doctrina ha hecho recaer sobre estos mecanismos una extendida sospecha de inconstitucionalidad, basada en la idea de que limita el derecho de asociaciones mucho más allá de lo que permite las exigencias de constitucionalidad como elemento integrante de la garantía institucional del Estado de Partidos. En concreto, el mecanismo actual de control basado en el registro podría ser incostitucional por dos razones: i) su carácter discriminatorio con respecto a las asociaciones y ii) su carácter preventivo.

i) Ninguno de los requisitos de constitucionalidad del artículo $6 \mathrm{CE}$ permite un trato discriminatorio con respecto a las asociaciones (salvo, como hemos dicho, el de democracia interna). No puede, por lo tanto, diseñarse un control más restrictivo para los partidos en un registro que el artículo 22 CE diseña, para todas las asociaciones, a los solos efectos de publicidad. En cualquier caso, aun aceptando el mecanismo del control incluido en el Registro, sólo podria aplicarse ante la existencia de indicios de «ilicitud penal«, por lo que no sería aplicable a los partidos que, aun utilizando mecios delictivos, no incurrieran en ninguno de los tipos del artículo 173 CP (ver DE OTTO, 1985; 89).

ii) Por otra parte, aun cuando el mecanismo del registro se extendiera a todas las asociaciones, persistiria su inconstitucionalidad, ya que el carácter preventivo del control iría en contra tanto del reconocimiento de libertad de creación del artículo 6 CE - para el caso concreto de los partidos-como en contra del «reconocimiento» del derecho de asociación, que por su propia naturaleza no permite controles preventivos ${ }^{4}$.

4 El hecho de que el control sea judicial, y no administrativo, no quita que siga dándose con carácter previo (ver SÁNCHEz MORON, 1979; 450). Que el juez dictamine a posteriori del depósito registral no significa que el control no siga siendo ex ante (ver sobre ello JIMÉNEZ CAMPO, 1981, que no duda en calificar el registro de partidos de verdadera «autorización previa»; en ese sentido, también DE OTTO, 1985; 99-102 y Álvarez Conde, 1983; 73). 
Cabe concluir, entonces, que de la incidencia del principio de constitucionalidad de «respeto a la Constitución y a la Ley» que integra la garantía institucional del Estado de Partidos, no puede deducirse una mayor restricción del derecho de asociación cuando el derecho se ejerce asociándose en partidos políticos. Esta mayor sujección de los partidos a la Constitución - que ha hecho incluso replantear la polémica jurídica en torno al momento de adquisición por el partido de personalidad jurídica plena- iria en contra de la bilateralidad y del carácter universal que tiene el mandato del artículo 9.1 CE.

A pesar de todo ello, el Registro sí podria haber aclarado algo sobre el segundo criterio de constitucionalidad del artículo $6 \mathrm{CE}$, la organización y funcionamiento interno del partido, que aunque problemático, sí podria, sin embargo, si mediara su desarrollo, desplegar una eficacia no tan limitada por la propia Constitución como el criterio del «respeto». En cualquier caso, hay que concluir que la existencia del registro de partidos es hoy inconstitucional y, además, o incluso antes, perfectamente inútil (ver DE OTTO, 1985; 124 y ss).

\section{EL ESTADO DE PARTIDOS Y LAS CANDIDATURAS ELECTORALES}

Entre las prescripciones básicas, usualmente con rango constitucional, de los regímenes electorales, se encuentra cierta restricción de la universalidad del sufragio pasivo, mayor que las posibles restricciones (por edad, por no inscripción en el censo, etc) que pueda tener la universalidad del sufragio desde el punto de vista activo. Estas restricciones tienen su justificación, como se sabe, en las llamadas causas de inelegibilidad e incompatibilidad.

Nuestra Constitución recoge también esas causas de inelegibilidad e incompatibilidad (art. $70 \mathrm{CE}$ ) y, como tales, son recogidas en la LOREG. El sentido de estas restricciones, tal como vienen recogidas en la Ley, es (ver ENTRENA, 1986; 73) doble: $i$ ) por un lado, «dejar fuera de la lucha electoral a los titulares de cargos que, por la indole de su función, podrían influir abusivamente sobre el electorado" (art. 6, 1 y 3 de la LOREG, en donde se incluye el caso especial de garantizar la posición de independencia de la familia real); ii) y, por otro lado, lo que es jurídicamente mucho más conflictivo (ver ENTRENA, 1986; 74 y un comentario a un auto del Tribunal Constitucional sobre el particular, en MARTIN RETORTILLO, 1985; 111-114), establecer una incapacitación para el sufragio pasivo como consecuencia de diferentes figuras delictivas (art. 6.3). 
La distinción entre elegible e inelegibles, así justificada, y la restricción que, en su virtud, se lleva a cabo de la universalidad del sufragio pasivo, no lesiona su contenido esencial. Existe, sin embargo, otra distinción que produce así mismo un «debilitamiento» de este derecho y que no encuentra su justificación en las razones anteriormente aludidas, sino en los efectos de la garantía institucional del Estado de Partidos: es la distinción que se da, no ya entre elegibles a inelegibles, sino entre elegibles y candidatos.

Acudiendo a este segundo debilitamiento del sufragio pasivo, se puede afirmar (CARRERAS-VALLÉS, 1977; 57) que el elegible -es decir, el no sujeto a causa de inelegibilidad - no es aún sino un "candidato en potencia». Para perfeccionar su carácter de tal deberá cumplir unos determinados requisitos: formales: la proclamación (regulada en el art. 47 LOREG); y no formales, o no establecidos juridicamente por la ley: la pertenencia o el respaldo por un partido politico o un grupo electoral que to incluya en su candidatura.

Es en este momento de restricción de la universalidad del sufragio pasivo cuando incide la influencia de los partidos políticos en el proceso electoral. Aunque su logica y su justificación es completamente diferente del anterior, bien puede ser analizado como su complemento o consecuencia. De esta forma, en la práctica «se delega en los partidos la "concreción" de los elegibles" (BASTIDA et al., 1980; 2166-17). No basta, pues, con ser elegible. Hay que ser, también candidato.

Analizaremos la influencia de los partidos en este segundo eslabón del debilitamiento del sufragio pasivo, desde la doble perspectiva que abre la garantia institucional del estado de Partidos: A) el principio de constitucionalización de los partidos fortalecerá el protagonismo de éstos en las candidaturas por ellos respaldadas; $B$ ) la existencia de criterios de constitucionalidad les impondrá determinadas cargas.

A) El fortalecimiento de la presencia de los partidos en las cantidaturas electorales tiene, a su vez, una doble lectura, ad intra y ad extra: 1) desde el primer primer punto de vista, es necesario estudiar la relevancia del partido como instrumento de control interior de su propia candidatura; 2) desde el segundo punto de vista, es necesario estudiar la prevalencia de las candidaturas de los partidos sobre las presentadas por otros tipos de agrupaciones.

1) El protagonismo de los partidos en el interior de sus propias candidaturas electorales ha venido en detrimento del protagonismo que podrian ostentar los propios candidatos en ella incluidos. La candidatura se convierte asi en una "candidatura de lista» y no en una mera «lista de candidatos". Esto restringe los derechos de los propios candidatos (lo que se hace tan evidente en algunos aspectos que ni siquiera se regula; por 
ejemplo, no se encuentra en la LOREG —al contrario que en el Código electoral francés (art. L 156) o en la Ley Electoral del Pais Vasco (art. 61)ninguna norma que prohiba a un candidato estar presente en más de una candidatura). El carácter bloqueado de la lista otorga al partido la capacidad para decidir la segunda distribución de escaños - la que tiene lugar en el interior de cada lista-, principio que se ha introducido también en las listas abiertas al Senado ${ }^{5}$. No obstante, el principio de unidad y estabilidad de la lista puede también funcionar con efectos contrarios al protagonismo de los partidos, ya que, a efectos de provisión de vacantes, es irrelevante que, con posterioridad al momento electoral, algún candidato dejara el partido o incluso ingresara en otro (ver ALBA, 1986; 1347), o que constara en ella con el carácter de «independiente», como efectivamente permite el artículo 172 de la LOREG.

Con todo, la mayor innovación que produce la LOREG en cuanto al protagonismo de los partidos ad intra de su propia lista -en tanto que el carácter de lista bloqueada se encontraba ya en el Real Decreto-Ley de 1977 - se introduce mediante la figura de los representantes electorales. El agudo análisis de Javier BALLARín (1986) sobre este aspecto conecta directamente la nueva regulación de esta figura con el ascenso del protagonismo de los partidos en el proceso electoral. La LOREG habla (art. 43) de unos "representantes generales" y de unos "representantes de candidaturas». Los primeros actúan expresamente «en nombre de los partidos, federaciones y coaliciones concurrentes" (art. 43.2) y como tales se presentan ante la Junta Electoral Central (art. 168). Se entiende que en su procedimiento de designación habrá que estar a lo que se regule, en el mejor de los casos, en los respectivos estatutos de cada partido. Estos representantes generales, por lo tanto, no representan a los candidatos, sino a los partidos políticos. Por el contrario, se especifica (art. 43.3 LOREG) que los representantes de las candidaturas «lo son de los candidatos incluidos en ellas". Sin embargo, estos representantes no son designados por los candidatos sino por el partido y, según la Ley, «reciben de éstos, por la sola aceptación de la candidatura, un apoderamiento general para actuar en procedimientos judiciales en materia electoral». En definitiva, se hace evidente: una deficiente regulación que incluso puede hacer plantearse por las características jurídicas de la representación que ostentan estos representantes; que el mecanismo de representación de las candidaturas pretende que «cada candidatura hable con un sola voz» (BALLARÍN, $1986,346)$; que los representantes de candidatura no son en ningún caso,

5 La lista de candidatos a Senadores se ha ido convirtiendo también progresivamente en una candidatura de lista. Asi, la LOREG regula un nuevo orden para la colocación de los candidatos, que no se hace ya alfabéticamente, sino por partidos políticos. $Y$ se introduce, junto a cada candidato, un suplente, con lo cual, en caso de vacante, ésta no es cubierta por el sguiente candidato más votado, sino por aquél; ver artículo 171 de la LOREG. 
representantes de los candidatos individualmente considerados; $y$ que todo ello refuerza el principio de unidad de lista y el de control por parte de los partidos de sus propios candidatos incluidos en ella. Lo cual es significativo si tenemos en cuenta las importantes funciones que a esos representantes se le reserva en todo el proceso electoral (ver una relación de estas funciones en BALLARIN , 1986; 351), y en particular, en relación con el control de los propios resultados electorales (ver más adelante).

2) El segundo efecto de la constitucionalización de los partidos se deduce del protagonismo que, cara al exterior, tienen las candidaturas respaldadas por ellos con respecto a aquellas otras que no lo están.

Como cauce para el ejercicio del derecho a la participación política (art. $23 \mathrm{CE}$ ) mediante modalidades no partidistas, la LOREG contempla la posibilidad de concurrencia a las elecciones de las «agrupaciones de electores». Estas agrupaciones revisten, en nuestro régimen electoral, un carácter esencialmente diferente del que puede observarse en otros países cercanos al nuestro. Todavía, en algunos de ellos, el no reconocimiento expreso del protagonismo de los partidos en los procesos electorales hace que bajo las "agrupaciones de electores" de las que hablan las leyes electorales, se cobijen auténticos partidos políticos. Ese no es nuestro caso. La recepción del protagonismo de los partidos en la LOREG, que es, como estamos viendo, evidente, dispensa de esta operación de camuflaje.

Bajo las agrupaciones de electores, entonces, hemos de entender exclusivamente las opciones electorales que deliberadamente, deciden no concurrir bajo la forma de un partido político (en este sentido, RUIZ NAVARRO, 1986; 369). Aunque, por otra parte, no dejaría de ser paradójico que, de la mano de las especiales trabas que se oponen a estas agrupaciones, el mismo ordenamiento que obligó durante algún tiempo a los partidos a aparecer bajo la forma eufemística de «agrupaciones electorales», obligara ahora a estas agrupaciones e incribirse y concurrir a las elecciones como si de partidos políticos se tratara.

La trabas que se ponen a las agrupaciones, debilitando esta modalidad del derecho de participación, se concretan, sobre todo, en la existencia de un número de firmas de aval para poder presentar la candidatura (ver art. 46 LOREG y el comentario sobre ello de RUIZ NAVARRO, 1986; 402-403). El objetivo de estas firmas, a cuyo fin se incluyeron también en 1977 , es consolidar los partidos políticos como agentes electorales. En algún caso (ALBA, 1986; 1410), se ha querido destacar que aquella necesidad -y el éxito que tuvo, en su momento, su formulación- no justifica sin embargo, su trasplante literal- y aun agravado - a nueve años vista de las primeras elecciones de la transición. Aquí, de nuevo, la LOREG muestra un carácter conservador con respecto a la normativa anterior, y por lo tanto, 
con respecto al modelo de consolidación de los partidos que se desarrolló a su amparo ${ }^{6}$.

B) El protagonismo de los partidos, ad intra y ad extra, en las candidaturas electorales, se encuentra, por lo tanto, a la altura de lo que sus presupuestos de constitucionalización nos anticipaban. Confirman (en frase de GARCIA COTARELO, 1985; 12), que, «como de la Iglesia, puede decirse que fuera de los partidos no hay salvación (o representación)". Era pues, de esperar, que la incidencia de la garantía institucional del Estado de Partidos se hubiera completado mediante la confirmación de los presupuestos de constitucionalidad.

Sin embargo, no ha sido así. La especificación que, en el terreno electoral, podria haber supuesto concretar el principio de organización interna democrática (art. $6 \mathrm{CE}$ ) en una selección interna democrática de los cantidatos electorales, no ha sido recogida por la LOREG. Aun concibiéndose ésta, también en la doctrina más reciente, como "contrapeso" a la existencia de listas cerrada y bloqueadas (ver ALBA, 1986; 1407), idea que nosotros podemos extender a contrapeso de la confirmación del principio de constitucionalización de la garantía institucional del Estado de Partidos, no se ha creído oportuno introducir ninguna regulación sobre el particular.

- La critica de ALBA $(1986 ; 1410)$ es lo suficientemente argumentada como para transcribirla en su totalidad. Afirma que «la nueva ley electoral, en ésta como en tantas otras materias, ha sido notablemente conservadora y ha optado por calcar sin más el modelo que propugnó el Real Decreto-Ley de 1977. Lo que en su momento pudo tener justificación en la especial situación política de aquella época, carece hoy de análogo basamento en la realidad de 1985. Con ello queremos decir que el porcentaje de firmas nos parece inusualmente elevado para lo que es práctica común en otros paises de nuestra órbita jurídica (...) El asentamiento y consolidación de los partidos políticos como instrumentos fundamentales de participación política, no pasa, no debe pasar, por yugular o dificultar la autoorganización política que la sociedad puede darse en determinados momentos a sí. misma. Rebajar el listón de firmas o cifrar éstas en un número fijo más asequible era una de la exigencias que podrian solicitarse a la nueva ley electoral. No ha sido así y, lo que es más extraño todavia, no parece desprenderse de la tramitación parlamentaria que nadie lo haya requerido...". Excepto en esta última extrañeza, que a estas alturas del trabajo creemos desterrada, la crítica de ALBA es perfectamente asumible por nosotros. Sobre ese último aspecto, AstaRLoA (1986; 1610 y ss) proporciona una jugosa anécdota parlamentaria: a lo largo de la tramitación de la LOREG, el número de firmas exigido para las agrupaciones en las elecciones municipales (art. 187) sufrió una elevación. Esta elevación se contenía en una enmienda transaccional del grupo socialista en la Comisión en el Congreso. Lo curioso del caso es que esta transacción no se apoyaba en ninguna enmienda anterior que fuera retirada por la presentación de ésta. Era, en realidad, una transacción inexistente. 


\section{EL ESTADO DE PARTIDOS Y LA CAMPAÑA ELECTORAL}

La incidencia de la garantía institucional del Estado de Partidos no se ciñe a las diferentes manifestaciones del derecho al sufragio que conforman el derecho electoral. También se extiende a las diferentes instituciones del sistema electoral. Se ha hablado, en este terreno, de la presencia de los partidos en las circunscripciones electorales, en la misma fórmula electoral utilizada y en la campaña electoral.

Por lo que hace a las primeras, es de común conocimiento que los partidos políticos pueden favorecer una división del territorio en circunscripciones electorales con la intención de favorecer las respectivas previsiones de voto. A pesar de la extrema sutilidad con que esta distribución en circunscripciones puede presentarse (ver NOHLEN, 1978; 110), parece que, sin embargo, la división en circunscripciones que preceptúa la CE, y que la hace coincidir con la provincia, no se puede incluir dentro de ninguna de aquella tácticas, aunque, en un principio, se extendieron las críticas en este sentido (ver una crítica de aquellas críticas en ALBA, 1986; 1309 y ss).

Por lo que hace a la fórmula electoral, hemos visto ya la funcionalidad que presentan las listas cerradas y bloqueadas para consolidar el poder de los partidos. A ello hay que añadir los efectos de la fórmula de D'Hondt, que, como se sabe, corrige la proporcionalidad de la distribución de escaños, haciéndola aparecer, sobre todo en circunscripciones pequeñas, como una fórmula en la práctica mayoritaria ${ }^{7}$. En cualquier caso, el efecto más decididamente facilitador del protagonismo de los partidos en cuanto a la fórmula electoral de distribución de escaños se encuentra en las disposiones especiales de la LOREG que afectan a las elecciones municipales.

En ese momento se produce una especial consecuencia de la prohibición para las agrupaciones de electores, no encuadradas en partidos, de poder constituir coaliciones electorales, que se deduce del articulo 44 LOREG; en su virtud, por ejemplo, estas agrupaciones nombran sólo representantes provinciales y no representantes generales ante la Junta Electoral Central, como hacen los partidos y las coaliciones y federaciones de partidos concurrentes (art. 168 LOREG).

7 La escasa proporcionalidad del régimen electoral español se arrastra desde la fijación de un mínimo de dos escaños al Congreso por cada provincia como circunscripción electoral, en el Real Decreto Ley de 18 de marzo de 1977 . Es consecuencia, como se sabe, de la acción combinada de la fórmula D'Hondt y circunscripciones electorales de pequeño tamaño. Para un análisis de los efectos de ambos factores, ver «proporcionalidad frente a circunscripción provincial», TORRES del Moral, 1980; 58 y ss. 
La imposibilidad de las agrupaciones de electores de coaligarse se traduce, en las elecciones municipales, en la existencia de claros efectos discriminatorios para el reparto de escaños en las Diputaciones Provinciales, que se realiza (art. 205 LOREG) atendiendo al número de votos obtenidos por cada candidatura en las elecciones municipales, distribuyéndose éstos por partidos judiciales. De esta forma, las diferentes agrupaciones electorales de ámbito municipal, al no poder coaligarse con otras agrupaciones del mismo partido judicial, se ven perjudicadas en el reparto de escaños de la Diputación Provincial.

La LOREG no soluciona expresamente este problema (ver un comentario en ASTARLOA, 1986; 1971), que estaba presente ya en la antigua Ley de Elecciones Locales, acusada, por esta razón, de poseer un «espíritu partidocrático» (EMBID, 1979), contra el que se pronunció, en su momento, alguna jurisprudencia ${ }^{8}$. Aunque el texto de la LOREG deja las cosas más o menos igual, se puede desprender de la voluntad del legislador una decidida intención a dejar fuera del reparto de escaños para las Diputaciones Provinciales a las agrupaciones de electores. Aunque en ello puede incidir la frecuente ideología conservadora de este tipo de agrupaciones electorales, no hay que olvidar que es precisamente en el ámbito municipal donde los fenómenos de candidaturas apartidistas se dan con mayor frecuencia.

En cualquier caso, en la institución del sistema electoral en donde se patentiza más la presencia de los partidos - por encima de su influencia sobre circunscripciones y fórmulas electorales-es en la regulación de la campaña electoral.

Las campañas electorales son inseparables de los procesos electorales de las sociedades desarrolladas. Pueden definirse (CARRERAS-VALLÉS), 1977; 60) como «aquel periodo de tiempo, anterior a la fecha de las elecciones, en que los candidatos, a través de los medios de comunicación - mítines, prensa, radio, televisión, etc- intentan ponerse en contacto con el cuerpo electoral para atraer el máximo número de votos».

Desde sus comienzos, las campañas electorales han sufrido también un profundo proceso de transformación (ver LOPEZ GUERRA, 1976), en el

8 Cfr. la sentencia de Audiencia Territorial de Barcelona de 27 de abril de 1979, que decide sobre el recurso planteado por la agrupación de electores «democraci i progres», junto con otras candidaturas, ante la decisión de la Junta Electoral de Zona de Lérida de prohibir que las agrupaciones de electores de diversos municipios se coligasen para el reparto de escaños de la Diputación Provincial en el partido judicial de Borjas Blancas. Ante la oscuridad de la Ley, el fallo estimó los argumentos de los recurrentes, debido al absurdo a que habría conducido otra interpretación, pues los independientes habian obtenido, en conjunto, 119 escaños de concejales de ese partido judicial, mientras que el partido que le seguia más de cerca lo hacía con sólo 47 concejales; ver un comentario de la sentencia en EMBID 1979. 
cual el ascenso del protagonismo de los partidos ha sido una de las notas características.

Así, la clasificación tradicional de las diferentes campañas, que podía establecerse en función de los medios de persuasión empleados, hoy debe ser desechada. En la actualidad, la característica dominante es de un profundo cambio en esos medios de persuasión. El cambio se define atendiendo a varios parámetros (según los recoge LOPEZ GUERRA, 1976; 98104): declive de la prensa de partido y ascenso de la campaña a través de prensa independiente o no militante; ascenso de la campaña a través de radio y televisión; profusa utilización de medios sofisticados de investigación social; importante presencia de técnicos y especialistas en marketing político; y pronunciado ascenso de los costes económicos de la campaña. En estas condiciones, se producen tanto importantes consecuencias para la estructura interna de los propios partidos, como "un cambio considerable de la posición de los partidos dentro del sistema político, así como en el papel de la organización estatal respecto a ellos».

El cambio de la posición de los partidos viene confirmado por «la respuesta del Estado" a todas estas transformaciones. Esta respuesta es la regulación, a través de normas jurídicas, de los diferentes aspectos de la campaña electoral. Ésta puede tener, así, una nueva definición: es, ahora, "aquel período de tiempo en que actos políticos que en otros momentos no son regulados, si lo son» (CARRERAS-VALLÉS, 1977; 61).

En la intervención legislativa en las campañas electorales, motivada sobre todo por la necesidad de regular la propaganda en radio y televisión, frecuentemente medios de titularidad pública, y de proveer de fondos económicos a los cada vez más elevados costes de las campañas, pueden observarse, a modo de principios inspiradores, tres grandes ideas (ver CARRERAS-VALLÉS, 1977; 61): i) garantizar la libertad de expresión; ii) garantizar la imparcialidad y neutralidad del Estado y iii) facilitar la igualdad de oportunidades de los diferentes candidatos, principalmente, controlando el volumen y la procedencia de los gastos electorales.

Entre las diversas consecuencias ${ }^{9}$ que el proceso de regulación de las campañas electorales ha traido consigo, se destaca la consolidación del Estado de Partidos. Ésta se ha desarrollado concediendo a los partidos especial protagonismo a lo largo de las diferentes fases por las que esta regulación ha pasado. Podemos hablar, desde una perspectiva global, de tres: 1) una fase de regulación de la financiación de las campañas; 2) una

- Lópz Guerra (1976; 105 y 108) destaca dos consecuencias marginales al proceso que ahora estudiamos. En primer lugar, el hecho de que se haya interrumpido la evolución de los partidos de masas hacia partidos "de más masas»; y, en segundo lugar, la mayor integración de los partidos en el Estado a que conduce la utilización de los nuevos medios de persuasión. 
segunda fase de regulación del acceso a los medios de comunicación de titularidad pública; y 3) una tercera fase de regulación de la misma legitimidad para realizar actos de campaña electoral (ver sobre todo ello DEL CASTILLO, 1985).

1) Por lo que hace a la regulación de la financiaciación, se ha intentado clarificar (ver BASTIDA et al., 1980; 221-223) dos importantes aspectos: los destinatarios de esta financiación y los mecanismos para el establecimiento de su cuantía. Ambas cuestiones no dejan de tener trascendencia, puesto que, de un lado, se decide financiar fundamentalmente partidos, y no todos ellos sino sólo los que demuestran realizar una «efectiva función electoral» —es decir, los partidos importantes-y, de otro lado, la distribución de financiación puede deparar algunas desigualdades en el sufragio, ya que no todos los votos tienen siempre valor a efectos de ser generadores de financiación. En la LOREG, la cuestión de la financiación se solventa (arts. 121 a 134) estableciendo un doble sistema de financiación pública y de control de los gastos electorales.

La financiación pública tiene lugar mediante unas subvenciones, concedidas por el Estado a partidos, federaciones, coaliciones o agrupaciones de electores concurrentes a las elecciones (art. 127.1). Estas subvenciones -a no confundir con las que se prevén en la Ley Orgánica de Financiación de los Partidos Politicos- no pueden en ningún caso superar el volumen de gastos declarados justificables por el Tribunal de Cuentas. De ellas se pueden solicitar adelantos (art. 127.2). Se ha destacado, con acento critico (MARIN ARIAS, 1986; 1065), el hecho de que éstos se concedan exclusivamente en función de haber obtenido representación parlamentaria en las anteriores elecciones generales (o, en su caso, en las municipales). Aún más extraño debería resultar el olvido del legislador, que al especificar quiénes pueden recibirlos, habla, exclusivamente, de «partidos, federaciones y coaliciones", con lo cual, o bien expresa la idea de que ninguna agrupación de electores llegará a obtener representación parlamentaria, o bien les niega implicitamente la posibilidad de percibir adelantos sobre las subvenciones que inmediatamente antes (art. 127.1) se les acaba de garantizar.

En cualquier caso, este olvido no se da cuando, inmediatamente después de regular los adelantos sobre las subvenciones, se establecen medidas sobre el control de los gastos electorales: asi, en el artículo 129 (“Ninguna persona física o jurídica puede aportar más de un millón de pesetas a las cuentas abiertas por un mismo partido, federación, coalición o agrupación, para recaudar fondos en las elecciones convocadas»); en el artículo 130 ("Se consideran gastos electorales los que realicen los partidos, federaciones, coaliciones o agrupaciones participantes en las elecciones desde el día de la convocatoria hasta el de la celebración de las elecciones por los siguientes conceptos»...); o en el articulo 131.1 («Ningún partido, federación, coalición o agrupación puede realizar gastos electorales que 
superen los límites establecidos en las disposiciones especiales de esta Ley"...).

2) Conforme ha ido creciendo la importancia de los grandes medios de comunicación (radio y televisión) en las campañas electorales, ha ido apareciendo y desarrollándose una regulación especifica del "derecho de antena" de las diferentes opciones concurrentes. Optando entre los distintos sistemas que nos ofrece el derecho comparado ${ }^{10}$, la LOREG (art. 59 y ss) establece un sistema de utilización de los medios públicos de comunicación del que se ha dicho (RUIZ NAVARRO, 1986; 569) que ufavorece en demasia a las grandes opciones políticas». Se diseña (art. 64.3) un baremo de distribución, para acceder al cual es necesario presentar candidaturas al 75 por 100 de las circunscripciones comprendidas en el ámbito de emisión del que se trate, y que beneficia: i) con diez minutos de emisión a partidos, federaciones o coaliciones que no concurrieron o no obtuvieron representación en las elecciones anteriores; ii) con veinte minutos a los partidos, federaciones o coaliciones que hubiesen obtenido entre el 5 y el 20 por 100 de los votos entonces emitidos y iii) con treinta minutos a los partidos, federaciones o coaliciones que hubieran alcanzado, al menos, un 20 por 100 de los votos emitidos. Es lógico que en el debate parlamentario sobre el particular se produjera (ver RUIZ NAVARRO, 1986; 590) una polarización de posturas entre partidos grandes y pequeños, se supone que divididos por la frontera del 20 por 100 de los votos. No obstante, también aquí se produce una discriminación anterior: las agrupaciones de electores tienen su regulación específica (art. 64.4). Pueden obtener acceso a los medios públicos, si constituyen una federación que logre llegar al menos al 75 por 100 de las circunscripciones del ámbito de emisión (puesto que, como sabemos, la misma LOREG prohibe las coaliciones de agrupaciones por encima del ámbito provincial). Pero esta federación no tendrá derecho, en ningún caso, a más de diez minutos de programación, es decir, al tiempo estipulado para los partidos, federaciones o coaliciones que no obtuvieron representación en las elecciones anteriores. De nuevo aquí el legislador ha olvidado $\longrightarrow$ ni siquiera ha llegado a imaginar - que una agrupación electoral hubiera podido obtener representación parlamentaria en unas elecciones anteriores (ver una crítica a esta discriminación en RUIZ NA-

10 Ruiz NavarRo (1986) clasifica en tres los sistemas europeos sobre el particular: nórdico (flexibilidad y poca regulación); británico (el mismo tiempo para las dos primeras grandes opciones y cuotas de antena menor para el resto de las formaciones) y continental (acceso en proporción a la representación parlamentaria). En general, las diferentes fórmulas deben optar por «o bien atribuir el mismo tiempo de antena a todos los partidos que concurren a las elecciones, o bien distribuir dichos tiempos en proporción al número de votos obtenidos por lo partidos en las anteriores elecciones equivalentes» (id.; 565). Matizando más, GaRcia CoTARELO (1985; 193 Y SS) distingue también varias formas de financiación. Ver también Del Castillo (1985; passim). 
VARRO, 1986; 593; por lo que hace el caso de las elecciones municipales, donde se reproduce, ver ASTARLOA, 1986; 1621).

3) Un posible tercer paso en la progresiva regulación de la campaña electoral lo constituye la definición jurídica de quiénes pueden legalmente llevarla a cabo. Esta regulación se ha llevado a cabo también entre nosotros, originado unas disposiciones (art. 50 LOREG) de las que se ha dicho (BALLARÍN, 1986; 433) que no tienen ninguna analogía en el derecho comparado próximo al nuestro. El núcleo de estas disposiciones se encuentra en el artículo 50.3 LOREG que establece que «...ninguna persona jurídica distinta de las mencionadas en el apartado anterior (el art. 50.2, que se refiere a candidatos, partidos, federaciones, coaliciones o agrupaciones de electores) podrá realizar campaña electoral a partir de la convocatoria de elecciones". El origen claro de esta disposición se encuentra en los precedentes habidos de campañas electorales realizadas por asociaciones no concurrentes a elecciones, en concreto, el caso de la campaña realizada por la Confederación de Empresarios de Andalucía con motivo de las primeras elecciones al Parlamento de aquella Comunidad Autónoma. El intento de prohibir el desarrollo de campañas a aquellos no concurrentes a las elecciones, difícilmente conjugable con la coletilla de «sin perjuicio de los establecido en el artículo 20 de la Constitución» con la que acaba el artículo, ha suscitado, sin embargo, algunos problemas en cuanto a su interpretación:

- En primer lugar, ha desatado la necesidad de contemplar en la misma ley (art. 50.1), como excepción, la llamada campaña institucional, cuya regulación presenta de por sí, algunos problemas (por ejemplo, los sujetos legitimados bajo la denominación "los poderes públicos» o la legitimidad de una campaña no sólo de información sino, como permite la ley, de «incentivación» al voto; ver sobre todo ello BALLARÍN, 1986; 434438 y ss).

- En segundo lugar,' los límites del debilitamiento del derecho a la libertad de expresión (art. $20 \mathrm{CE}$ ) $-\mathrm{y}$ del derecho a la participación política (art. $23 \mathrm{CE}$ ) - que puede producirse por este efecto de la garantia institucional del Estado de Partidos. BALLARÍN (1986; 443 y ss) cree ver la ratio del precepto en el control de gastos electorales ( $y$ no en la consolidación del Estado de Partidos), lo que le impone una gran restricción interpretativa en cuanto a sus posibilidades de despliegue ${ }^{11}$.

11 Dice BALLARIN (1986; 446-47) que «la ratio del precepto no debe buscarse en el intento de restringir la posibilidad que las personas juridicas tienen de expresar sus puntos de vista ante las distintas opciones electorales; ni siquiera busca aquél limitar su capacidad de influencia sobre el cuerpo electoral en general. Com- 
- En tercer lugar, los límites temporales de la prohibición, habida cuenta de que la misma ley, a renglón seguido, se preocupa de especificar (art. 53) que la prohibición de hacer campaña electoral antes o después de sus fechas legales no incluye la actividad normal de los partidos, coaliciones y federaciones (de nuevo se excluyen a las agrupaciones de electores) en el ejercicio de sus funciones constitucionalmente reconocidas "en particular, en el artículo 20 de la Constitución" (sic) ${ }^{12}$.

\section{EL CONTROL DE LA INCIDENCIA DEL ESTADO DE PARTIDOS SOBRE EL PROCESO ELECTORAL}

De la incidencia del Estado de Partidos sobre los diferentes institutos del derecho y del sistema electoral, en particular sobre el registro de partidos, sobre las candidaturas electorales y sobre la campaña electoral, cabe deducir que existe un mayor despliegue de los elementos que confirman la constitucionalización de los partidos que de los elementos que desarrollan la existencia de los criterios de constitucionalidad.

porta el precepto, si, limitaciones a una y otra cosa, pero esas limitaciones se establecen para asegurar la efectividad de la organización jurídica de la campaña, y en particular, del principio de igualdad entre las candidaturas que la organización jurídica pretende lograr (..) entendemos que lo que aqui se prohibe a las personas jurídicas distintas de las enumeradas en el apartado segundo (las concurrentes a las elecciones) es toda actividad material de campaña que pueda reputarse una forma de financiación indirecta, material, de la misma, por constituir, desde el punto de vista económico, una contribución relevante a la campaña realizada por alguna candidatura. Estas actividades deben poder imputarse a las personas juridicas para estimarse prohibidas, y deberán serlo, de nuevo, atendiendo al dato de la financiación, y no a otros que puedan ser engañosos".

12 Esta formulación, olvidando, que del artículo $20 \mathrm{CE}$ no se desprenden funciones, sino derechos, simboliza el meollo de la cuestión que venimos tratando: si, como parece querer la LOREG, el derecho a la libertad de expresión del artículo 20 CE fuera una efunción» más de los partidos, asistiriamos a la completa invasión de la garantía institucional del Estado de Partidos sobre la esfera de los derechos fundamentales. Que esta invasión no se produzca, y que en consecuencia, se genere una tensión entre ambos extremos, se debe, como sabemos, a que los derechos subjetivos de los ciudadanos tienen una esfera más amplia que las atribuciones funcionales que se proyectan sobre los partidos, y toleran sólo un debilitamiento, pero no su completa eliminación, por efecto de éstas. En cualquier caso, con ella, se permite en la práctica proseguir con las precampañas de los partidos políticos (ver sobre ello BaLLARIN, 1986; 485 y ss). 
Hablábamos de tres parámetros que nos permitirian investigar el presunto equilibrio o desequilibrio de la relación entre la garantía institucional del Estado de Partidos y ciertos derechos fundamentales en este momento de la creación de la representación. Parece que en lo que hace a los dos primeros se puede concluir que, por un lado, existen previsiones constitucionales y legales sobre esta incidencia pero que, por otro lado, estas previsiones han puesto más énfasis en el desarrollo de un elemento de la garantía (la constitucionalización de las funciones de los partidos) que en el otro (constitucionalidad en el ejercicio de esas funciones).

Veamos ahora el tercer parámetro: se trata de la existencia o no de mecanismos que permitan el control sobre el debilitamiento de los derechos subjetivos que trae consigo todo lo anterior.

La situación de los partidos en cuanto sujetos susceptibles de ser controlados -o de instar algún tipo de cotrol- desde un punto de vista jurídico es, por lo que hace al proceso electoral, consecuencia de una situación general alguna vez calificada de «laberíntica» (DE LA OLIVA, 1979). $\mathrm{El}$ origen de todo ello se encuentra, probablemente, en la retirada de las inciales propuestas del momento constituyente en orden a aforar todo lo relativo a la actuación de los partidos al Tribunal Constitucional y, en consecuencia, su sujeción a la jurisdicción ordinaria, como el mismo TC ha reconocido (ver STC de 2 de febrero de 1981), no menos real por la unanimidad doctrinal (cfr. ÁLVAREZ CONDE, 1983; 73) desatada en su contra.

Muestra de esta compleja situación es la convivencia de procesos penales y civiles en posibles causas de ilegalización del partido (ver SANTAMARÍA PASTOR, 1985; 96) y la poca armonización de estos controles, por ejemplo en lo que hace a la fiscalización de la posible denegación de inscripción en el Registro de partidos o a la iniciación de procedimientos de ilegalización como consecuencia de esa denegación (ver DE OTTO, 1985; 109 y ss).

Por lo que hace al control de las elecciones, la figura del partido se encuentra algo más detallada, aunque no por ello deja de suscitar problemas. En general, cabe decir que se prevén dos instancias de control: a) administrativa y b) judicial. En ambas se produce una importante participación de los propios partidos políticos en el control del proceso electoral: a) en lo que hace al control administrativo, por la vía de la presencia del partido en la propia administración electoral; b) en lo que se hace al control judicial, por la via de las legitimaciones procesales que se sustancian en ellos. Se produce, por lo tanto, un activo protagonismo de los partidos, tanto "interior" como "exterior" (la distinción es de BASTIDA, et al. 1980; 218) en los mecanismos de control del proceso electoral.

a) Así, en lo que hace a la administración electoral, se produce una fuerte presencia de los propios partidos en las diversas «juntas electorales», la pieza básica de la nueva administración electoral diseñada por la 
Ley (LOREG arts. 8 y ss). De esta manera, la Junta Electoral Central, situada en la cúspide de esta administración, se compone (art. 9 LOREG) de ocho vocales Magistrados del Tribunal Supremo y de cinco vocales, catedráticos de Derecho, designados «a propuesta conjunta de los partidos, federaciones, coaliciones o agrupaciones de electores con representación en el Congreso de los Diputados».

La toma en consideración de la representación en el Congreso como criterio para la designación de los vocales no dota (ver CAZORLA PRIETO, 1986; 117) a la Junta Electoral Central de naturaleza parlamentaria. Esta circunstancia; unida a que el carácter de la propuesta «conjunta» de la que habla la Ley no ha sido interpretado como propuesta unánime (id.; 121) y a que haya que tener en consideración la representación de cada uno de los partidos en caso de que se utilice el procedimiento subsidiario que prevé el mismo artículo 9 (designación por la Mesa del Congreso en caso de que la primera propuesta «conjunta» no llegara a formularse), dota a la elección de los vocales no procedentes del Poder Judicial de una clara tendencia partidista.

En cualquier caso, el principio de presencia de los propios partidos se despliega a lo largo de toda la administración electoral, lo que, en ocasiones, ha producido algún problema en orden a la calificación jurídica del órgano en cuestión (ver sobre la «atipicidad» de la Comisión de Radio y Televisión, RUIZ NAVARRO, 1986; 604).

b) En segundo lugar, en lo que hace a los recursos contenciososelectorales (arts. 109 y ss LOREG), el artículo 110 LOREG legitima para su interposición: i) a los candidatos, ii) a los representantes de las candidaturas y iii) a los partidos políticos, asociaciones, federaciones y coaliciones concurrentes. Se ha llegado a criticar esta legitimación (ENTRENA, 1986; 991) por excesivamente amplia, llegándose a mostrar una opinión contraria a las intenciones del precepto, que parecen haber sido «que la sala oiga a cuantos tienen algo que decir en el proceso", aunque, con ello no se hace «sino propiciar inconvenientemente las discordancias internas de los partidos».

Esta aparente generosidad en la legitimación para plantear los recursos electorales no es, sin embargo, tan evidente como pueda parecer a primera vista. Hay que tener en cuenta que, de entrada ( $y$ al contrario de lo que hacen el Código Electoral Francés o las disposiciones similares del Reino Unido), no se consideran legitimados para iniciar el control los propios electores, en tanto que tales, cuya presencia en el proceso electoral se sustancia tan sólo mediante la posibilidad de ser designados, por azar, presidentes o miembros de una mesa electoral (art. 26.2 LOREG) o mediante su presencia en el acto público de recuentos de votos.

Por otra parte, la legitimación simultánea de candidatos, representantes y partidos ha de ser puesta en conexión con la relevancia que a lo 
largo de la LOREG se les concede a los segundos como delegados directos de estos últimos y con los problemas que la «representación» de los propios candidatos que los representantes ostentan plantea. Es preciso reconocer que, de esta forma, se completa un sucesivo trasvase en la titularidad de la capacidad principal para controlar el proceso electoral: originariamente los electores, después los candidatos y, por fin, los partidos. Ello se debe, sin duda, a razones funcionales y de eficacia. Pero se descubre también junto a ésta (ver BALLARÍN, 1986; 344) una razón política: el hecho es que la institución del representante de la candidatura es un medio idóneo para asegurar al partido el control sobre ellas. En definitiva, el partido político se convierte en protagonista del procedimiento. 


\section{REFERENCIAS BILBIOGRÁFICAS}

ABENDROTH, Wolfang (1964): «El problema de la democracia interna de partidos y asociaciones en la República Federal de Alemania», en id., Sociedad antagónica y Democracia Política. Barcelona, Grijalvo, 1973, págs. 409-451.

AlBA, Manuel (1986): "Comentarios a los artículos 161 a 172», en CAzorla PRieto, (dir).

Álvarez Conde, Enrique (1983): El Régimen político Español. Madrid, Tecnos.

Álvarez Conde, Enrique y Gonzalez Hernandez, Juan Carlos (1985): «Prólogo» al Código de Derecho Electoral Español. Madrid, Tecnos, págs.12-46.

AstarloA, Igancio (1986): «Comentarios a los artículos 179 a 191, 194 a 201, 204 a 208, disp. adic. 1. ${ }^{a}$ y disp. adic. 3. ${ }^{\prime \prime}$, en CAZORLA Prieto, (dir).

BALLARIN, Javier (1986): «Comentarios a los artículos 43, 50 a 58, 76 a 79 y 95-108», en Cazorla Prieto, (dir.).

BAstidA, Francisco; Punset, Ramón y Otto, Ignacio (1980): Lecciones de Derecho Constitucional. Oviedo.

Carreras, Frances y Vallés, Josep (1977): Las Elecciones. Barcelona, Blume.

Castillo, Pilar del (1985): La financiación de partidos y candidaturas en las democracias occidentales. Madrid, CIS.

Cazorla Prieto, Luis (1986): «Comentarios al preámbulo y a los artículos 9, 13.1, 16 a 17, 22, 42, 86 a 89, 91 a 94, 119 a 120, disp. adic. 2." disp. trans. 1. ${ }^{a}$,.$^{a}$ y $5 .^{a}$ y disp. final», en $i d$. , (dir), Comentarios a la Ley Orgánica del Régimen Electoral General. Madrid, Civitas. 
EMBID IRUJo, Antonio (1979): «Una interpretación judicial de la Ley de Elecciones Locales: sobre la posibilidad de unión de las listas de concejales independientes a efectos de atribución de puestos de diputación provincial», en REDA, n. ${ }^{\circ} 22$, págs. 437-441.

EnTRENA Cuesta, Ramón (1986): "Comentarios a los artículos 1.1, 1.2, 2 al 7, 49, 109 al 117, 154 al 160, 176 al 178, 202 al 203», en Cazorla Prieto, (dir).

ESTEBAN, Jorge de (1977): «La razón de las elecciones» y «Conclusión general", en id. y otros, El proceso electoral. Barcelona, Labor, págs. $11-34$ y $343-47$.

FERnANDEZ SEgAdo, Francisco (1986): Aproximación a la nueva normativa electoral. Madrid, Dykinson.

Garcia Cotarelo, Ramón (1985): Los partidos políticos. Madrid, Sistema.

Garcia Pelayo, Manuel (1986): El Estado de Partidos. Madrid, Alianza.

JIMÉNEZ CAMPO, Javier (1981): "La intervención estatal del pluralismo». en REDC, $n .^{\circ} 1$, págs. 161-183.

LAWSON, Kay (1978): “Constitutional change and party development in France, Nigeria and United States», en MAISEL y CoOPER (eds.), Political parties: development and decay. Beverly Hills, SAGE pub.

LaWson, Kay (1980): “Introducción" en id. (ed)., Political parties and linkage: a comparative perspective. New Haven and London, Yale Univ. Press.

LOPEZ GUERRA, Luis (1976): «Sobre la evolución de las campañas electorales y la decadencia de los partidos políticos de masas», en REOP, n. ${ }^{\circ}$, págs. 91-110.

MARIN ARIAS, Manuel (1986): “Comentarios a los artículos 121 a 134, 147 a 175 y 192 a 193», en Cazorla Prieto, (dir.).

MARTIN RETORTILlo, Lorenzo (1985): El 23-F. Sus secuelas juridicas en la jurisprudencia del Tribunal Constitucional. Madrid, Civitas.

NOHLEN, Dieter (1978): Sistemas electorales del mundo. Madrid, CEC, 1981. 
Ollero, Carlos (1949): El derecho constitucional de posguerra. Apuntes para su estudio. Barcelona, Bosch.

OLIVA, Andrés DE LA (1979): «El laberinto procesal de los partidos políticos», en $R D P I, \mathrm{n}^{\circ}{ }^{3}$, págs. $559-579$.

OTTO, Ignacio DE (1985): Defensa de la Constitución y partidos politicos. Madrid, CEC.

RODRIGUEZ DIAZ, Angel (1987): «Un marco para el estudio de la representación política en los sistemas democráticos», en REP, $n{ }^{\circ}$ 58 , págs. $137-190$.

Rubio LloRente, Francisco (1979): «La Constitución como fuente de Derecho, en La Constitución Española y las fuentes del Derecho. Madrid, Dirección General de lo Contencioso del Estado, vol. I, págs. 53-74.

Ruiz Navarro, José Luis (1986): "Comentarios a los artículos 44 a 48, 59 a 75,80 a 85, 118 y 173", en Cazorla Prieto, (dir.).

SANTAMARIA PASTOR, Juan Alfonso (1985): "Comentarios al artículo 6", en Garrido, (dir.), Comentarios a la Constitución. Madrid, Civitas, $2 .^{\mathrm{a}}$ ed.

SchmitT, Carl (1928): Teoría de la Constitución. Madrid, Alianza Editorial, 1982.

TORRES DEL MORAL, Antonio (1975): «Democracia y representación en los orígenes del Estado Constitucional», en REP, $\mathrm{n}^{\circ} 203$, págs. 145-212.

—: (1980): “Composición del Congreso de los Diputados", en RFDUC, n. ${ }^{\circ} 58$, págs. $29-69$.

-: (1982): “Crisis del mandato representativo en el Estado de Partidos", en RDP, n. ${ }^{\circ} 14$, págs. 7-30.

VEGA, Pedro dE (1977): «Presentación», en id., Teoría y práctica de los partidos políticos. Madrid, EDICUSA.

VIRGA, Pietro (1948): / partido politico nell'ordinamento giuridico. Milano, Giuffrè. 